(2) Open Access Full Text Article

\title{
Impact of metoprolol treatment on mental status of chronic heart failure patients with neuropsychiatric disorders
}

This article was published in the following Dove Press journal:

Drug Design, Development and Therapy

25 January 2017

Number of times this article has been viewed

\author{
Xuelu Liu' \\ Xueming Lou' \\ Xianliang Cheng ${ }^{2}$ \\ Yong Meng' \\ 'Department of Cardiology, \\ ${ }^{2}$ Department of Endocrinology, The \\ Second Affiliated Hospital of Kunming \\ Medical University, Kunming, Yunnan, \\ People's Republic of China
}

Background: Metoprolol treatment is well established for chronic heart failure (CHF) patients, but the central nervous system side effects are often a potential drawback.

Objective: To investigate the impact of metoprolol treatment on change in mental status of CHF patients with clinical psychological disorders (such as depression, anxiety, and burnout syndrome).

Methods: From February 2013 to April 2016, CHF patients with clinical mental disorders received metoprolol (23.75 or $47.5 \mathrm{mg}$, qd PO, dose escalated with $23.75 \mathrm{mg}$ each time until target heart rate $[\mathrm{HR}]<70 \mathrm{bpm}$ was achieved) at the Second Affiliated Hospital of Kunming Medical University. Mental status was assessed by means of the Hospital Anxiety and Depression Scale (HADS) and the Copenhagen Burnout Inventory (CBI) scale. The primary outcome assessed was change in mental status of patients post-metoprolol treatment and the association with reduction in HR achieved by metoprolol.

Results: A total of 154 patients (median age: 66.39 years; males: $n=101$ ) were divided into eight groups on the basis of their mental status. HR decreased significantly from baseline values in all the groups to $<70 \mathrm{bpm}$ in the 12 th month, $P \leq 0.0001$. The HADS depression and CBI scores significantly increased from baseline throughout the study frame ( $P \leq 0.0001$ for all groups), but a significant decrease in the HADS anxiety score was observed in patients with anxiety ( $P \leq 0.0001$ for all groups). Regression analysis revealed no significant correlation in any of the groups between the HR reduction and the change in the HADS/CBI scores, except for a change in the CBI scores of CHF patients with depression $(P=0.01)$, which was HR dependent.

Conclusion: Metoprolol treatment worsens the depressive and high burnout symptoms, but affords anxiolytic benefits independent of HR reduction in CHF patients with clinical mental disorders. Hence, physicians need to be vigilant while prescribing metoprolol in CHF patients who present with mental disorders.

Keywords: metoprolol, chronic heart failure, HADS anxiety and depression, high burnout, CBI scale, heart rate

\section{Introduction}

Psychological disorders are common among patients with cardiovascular diseases. According to a literature review over the past decade, the prevalence rates of depression and anxiety among chronic heart failure (CHF) patients were $10 \%-60 \%$ and $11 \%-45 \%$, respectively. ${ }^{1} \beta$ blockers are widely used to treat $\mathrm{CHF}$ as several randomized clinical trials report their use to decrease hospitalizations and to enhance survival and wellbeing of heart failure (HF) patients. ${ }^{2-7}$ However, earlier reports on the possible side effects of $\beta$ blockers on the central nervous system (CNS), including the manifestation 
of depression ${ }^{8-12}$ and anxiety, ${ }^{13}$ have placed $\beta$ blockers on a controversial platform despite the well-established benefits. Cardiovascular researchers believe that peripheral effects of $\beta$ blockers on the heart and kidneys lead to decreased chronotropy and inotropy, as well as lower blood pressure, all of which cause fatigue, decreased energy, and sexual dysfunction that may be interpreted as symptoms of newonset depression. ${ }^{14}$ A recent study by Burkauskas et $\mathrm{al}^{15}$ reconfirmed the association between $\beta$ blocker use and psychological function in patients with coronary artery disease. In contrast, Ranchord et $\mathrm{al}^{16}$ reported that $\beta$ blocker therapy was not associated with an increase in depressive symptoms in acute myocardial infarction patients. This discrepancy may be based on the individual $\beta$ blocker used and its lipophilicity, as highly lipophilic $\beta$ blockers are associated with the highest level of depressive symptoms. ${ }^{17,18}$ On the other hand, although less research has been conducted on the association between the use of $\beta$ blockers and symptoms of anxiety, few studies report anxiolytic benefits, especially with metoprolol. ${ }^{19-21}$ However, these studies were not confined to patients with already existing clinical psychological disorders along with CHF. Recently, Brouwers et $\mathrm{al}^{22}$ studied the antidepressant effects on cardiac function and mortality and reported that the use of antidepressants in HF patients is associated with increased risk of all-cause and cardiovascular mortality. Similarly, it is of paramount importance to inversely study the $\beta$ blocker effects on changes in psychological behavior in HF patients, as earlier reports on adverse associations have potentially limited the use of $\beta$ blockers in vulnerable patients. Furthermore, emotional stress due to depression or anxiety results in burnout syndrome manifested as fatigue and exhaustion. It is believed that burnout syndrome may be an overlap of depression or anxiety disorders. ${ }^{23}$ A recent study reported a $4.1 \%$ prevalence of burnout syndrome and approximately $80 \%-90 \%$ stress among acute coronary syndrome patients. ${ }^{24}$ However, the prevalence in HF patients has not been reported till date, yet it is plausible that a similar rate will be observed. Therefore, we prospectively investigated the impact of metoprolol (a moderately lipophilic $\beta$ blocker) treatment on change in the mental status (depression, anxiety, and burnout syndrome) of CHF patients.

\section{Methods \\ Study design}

This is a prospectively designed single-center study executed from February 2013 to April 2016 using patients as their own controls. The protocol was approved by the Institutional Review Board of the Second Affiliated Hospital of Kunming
Medical University and conformed to the Declaration of Helsinki and its subsequent revisions.

\section{Selection of patients and grouping}

$\mathrm{CHF}$ patients with resting heart rate $(\mathrm{HR})>80 \mathrm{bpm}$ and newly diagnosed with neuropsychiatric disorders such as depression and anxiety using the Hospital Anxiety and Depression Scale (HADS) questionnaire and high burnout status using Copenhagen Burnout Inventory (CBI) scores at the Second Affiliated Hospital of Kunming Medical University were included in the study. All the patients were included in the study only after obtaining a signed informed consent.

Certain categories of patients were excluded from the study. They included patients with bradycardia (resting HR $<60 \mathrm{bpm}$ ), systolic blood pressure $<90 \mathrm{mmHg}$, those who had used metoprolol in the recent 3 months, those with $<6$ months expected survival, pacemaker-dependent patients, those with contraindications to $\beta$ blockers, those who were currently using Class I or Class III antiarrhythmic agents, tricyclic antidepressants, anxiolytics or any other CNS medications, and those who had undergone coronary bypass surgery or experienced a recent heart attack.

\section{Treatment intervention and follow-up}

Baseline data were collected from patients prior to treatment with initial 23.75 or $47.5 \mathrm{mg}$ qd PO metoprolol continuous release tablets (Betaloc ${ }^{\circledR} \mathrm{ZOK}$; AstraZeneca, Södertälje, Sweden), and dose escalated in patients not responding to initial dose with $23.75 \mathrm{mg}$ every 7 days until the target HR level (60-70 bpm) was achieved during follow-up. The average dose used to reach the target goal was $99.75 \mathrm{mg}(47.5-142.5 \mathrm{mg})$. All patients were followed up at $1,3,6$, and 12 months from intervention for final outcomes measurement.

\section{Study outcomes}

The primary outcomes were change in HADS depression and HADS anxiety scores along with CBI average scores in CHF patients with clinical psychiatric disorders post-metoprolol treatment in the 12th month. The secondary outcome was to evaluate the correlation between $\mathrm{HR}$ reduction and mental status.

\section{HR measurement}

Resting HR at baseline and 1, 3, 6, and 12 months postmetoprolol intervention was measured by electrocardiography after 3 minutes of rest. 


\section{Outcome assessment tools}

The mental status of patients was assessed during each follow-up visit using HADS, which is a self-assessment scale (from 0 to 3 frequencies and scoring of 0-21 for each question) comprising 14 questions for evaluating the current severity of depression and anxiety. An average HADS score $>7$ represents the presence of anxiety or depression, with the highest score reflecting marked impairment. ${ }^{25}$

Burnout was measured using the CBI scale, which is a reliable and validated 19-item questionnaire to evaluate exhaustion and its attribution by the person using scales on personal burnout (6 items on physical and psychological exhaustion), work-related burnout (7 items attributed to exhaustion at work), and client-related burnout (6 items on exhaustion attributed to work with clients). In this study, only personal burnout was assessed, which had five response categories on a Likert scale, namely, "never", "seldom", "sometimes", "often", and "always". Each scale ranged from 0 to 100 points, with 100 indicating the highest level of burnout. ${ }^{26}$

\section{Statistical analyses}

All analyses were carried out on $\mathrm{R}$ (version 3.2.2) statistical software. Baseline characteristics are reported as descriptive data with counts, percentages, and mean \pm standard deviation. Differences in HADS and CBI scores at different follow-up periods were compared with baseline using repeated measures one-way analysis of variance, followed by the post hoc Dunnet's multiple comparison test and $\chi^{2}$ tests as appropriate. The Pearson correlation analysis was performed to estimate the association between mental status and HR reduction achieved with metoprolol. A $P$-value of $<0.05$ was considered statistically significant for all the analyses.

\section{Results}

\section{Baseline characteristics}

A total of 169 patients were included in the study, of whom 11 patients were excluded as they were intolerant to metoprolol dose increments and 4 patients were lost to follow-up. Finally, data of 154 patients (median age: 66.39 years; males [ $n=101]$, females $[n=53]$ ) were obtained in this study (Figure 1).

At baseline, the mean glomerular filtration rate was found to be $73.9 \pm 26.8 \mathrm{~mL} / \mathrm{min} / 1.73 \mathrm{~m}^{2}$, and the mean body mass index was $23.85 \pm 3.62 \mathrm{~kg} / \mathrm{m}^{2}$. The majority of the patients were New York Heart Association Class III/IV $(n=145,94.15 \%)$, had a previous history of stroke $(n=137$, $88.96 \%)$ and hypertension $(\mathrm{n}=115,74.67 \%)$, and were on

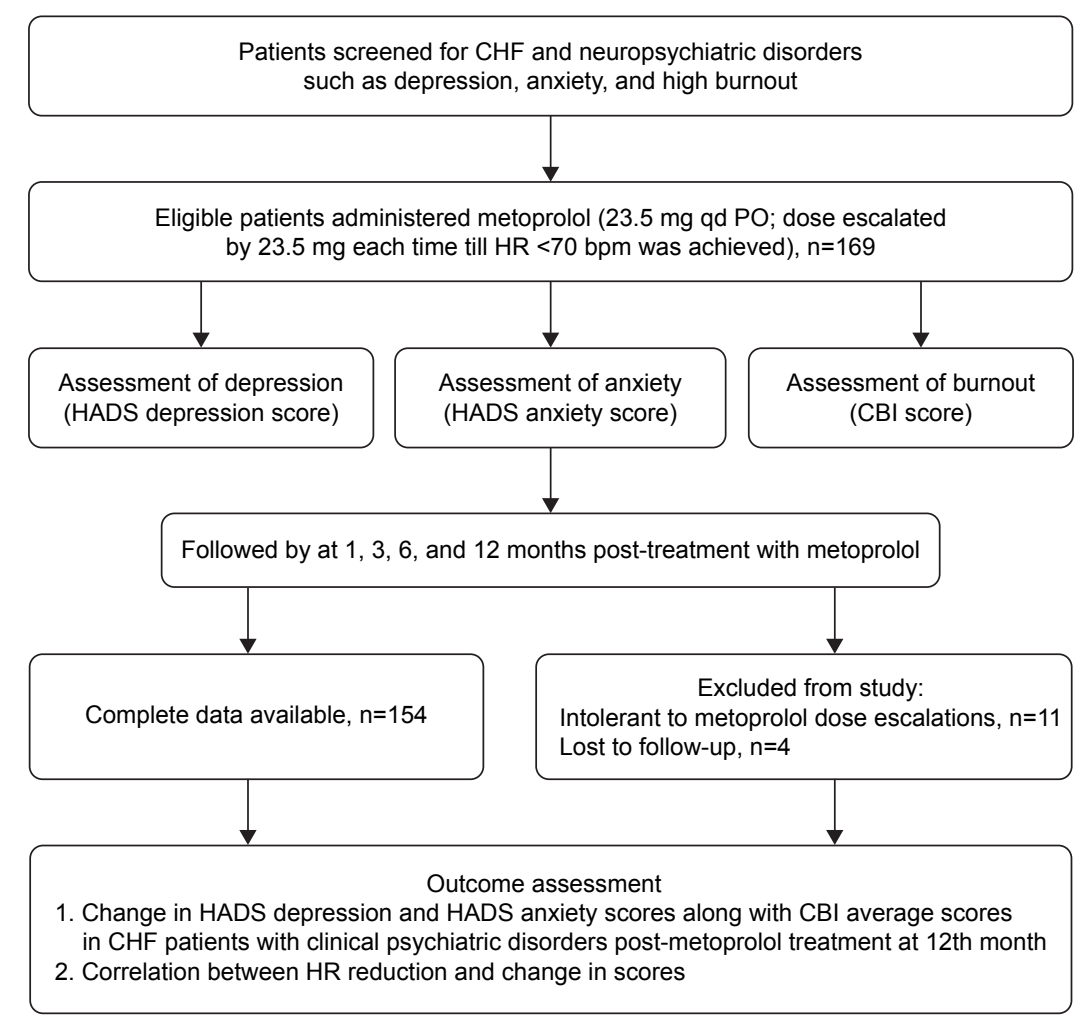

Figure I Study flowchart.

Abbreviations: CHF, chronic heart failure; HADS, Hospital Anxiety and Depression Scale; CBI, Copenhagen Burnout Inventory; HR, heart rate. 
angiotensin-converting enzyme inhibitors/angiotensin receptor blockers $(n=149,96.75 \%)$ and antithrombotic medication $(n=146,94.80 \%)$. None of the patients were on CNS medications (including anxiolytics and antidepressants). Details on the baseline characteristics are reported in Table 1.

\section{Metoprolol-induced HR reduction}

To assess the primary outcomes, patients were divided into eight groups on the basis of their mental status, as shown in Table 2. The average metoprolol dose required to reach the target HR goal was $99.75 \mathrm{mg}$. The average resting HR as measured by resting electrocardiogram decreased significantly from baseline values in all the groups to $<70 \mathrm{bpm}$ in the 12 th month, $P<0.0001$ (Table 2).

\section{Depressive effects of metoprolol}

Metoprolol treatment was observed to result in a significant rise in the HADS depression score from baseline (10.00 \pm 0.20$)$ at month 1 follow-up $(10.76 \pm 1.78 ; P \leq 0.05)$, which remained stable through 12 months. The HADS depression score was highest in patients with both depression and anxiety ( $7.75 \pm 0.96$ vs $13.70 \pm 1.40 ; P \leq 0.0001$ compared to patients with only $\mathrm{CHF}$ ) which remained stable throughout the study frame (13.64 \pm 2.20 vs $13.70 \pm 1.40$, baseline vs 12 th month). Although the HADS depression score was highest in patients with depression + anxiety + high burnout syndrome, the scores did not change post-metoprolol treatment. Depressive

Table I Baseline characteristics of overall patient population

\begin{tabular}{|c|c|}
\hline Patient characteristics $(n=154)$ & $\mathbf{N}(\%)$ \\
\hline Age, median years & 66.39 \\
\hline Male & I0I (65.58) \\
\hline Female & $53(34.4 I)$ \\
\hline \multicolumn{2}{|l|}{ Comorbidities } \\
\hline Hypertension & II 5 (74.67) \\
\hline Diabetes mellitus & $101(65.58)$ \\
\hline Coronary artery disease & $99(64.28)$ \\
\hline Stroke & 137 (88.96) \\
\hline Cardiac disease family history & $54(35.06)$ \\
\hline Smoking & III (72.07) \\
\hline Alcohol & $86(55.84)$ \\
\hline History of MI & $59(38.31)$ \\
\hline BMI, mean (SD), kg/m² & $23.85 \pm 3.62$ \\
\hline GFR, mean (SD), $\mathrm{mL} / \mathrm{min} / 1.73 \mathrm{~m}^{2}$ & $73.9 \pm 26.8$ \\
\hline NYHA Class III-IV & $145(94.15)$ \\
\hline \multicolumn{2}{|c|}{ Concomitant medications at baseline } \\
\hline ACEIs/ARBs & $150(97.40)$ \\
\hline Diuretics & $145(94.15)$ \\
\hline Digoxin & II 4 (74.02) \\
\hline Antithrombotic agents & $146(94.80)$ \\
\hline
\end{tabular}

Abbreviations: MI, myocardial infarction; BMI, body mass index; GFR, glomerular filtration rate; NYHA, New York Heart Association; ACEls, angiotensin-converting enzyme inhibitors; ARBs, angiotensin receptor blockers.
Table 2 Heart rate changes after metoprolol treatment

\begin{tabular}{llll}
\hline Groups & Baseline & Month I 2 & P-value* \\
\hline Depression $(n=25)$ & $83.48 \pm 7.46$ & $64.68 \pm 3.44$ & $<0.000$ I \\
Anxiety $(n=15)$ & $83.73 \pm 7.60$ & $64.13 \pm 2.58$ & $<0.000$ I \\
High burnout $(n=16)$ & $82.56 \pm 7.33$ & $64.68 \pm 2.93$ & $<0.000$ I \\
Depression + anxiety $(n=I 7)$ & $81.88 \pm 7.25$ & $65.23 \pm 3.30$ & $<0.000$ I \\
Anxiety + high burnout $(n=21)$ & $81.23 \pm 3.85$ & $65.52 \pm 3.60$ & $<0.000$ I \\
Depression + high & $84.2 \pm 7.93$ & $64.66 \pm 3.06$ & $<0.000$ I \\
burnout $(n=15)$ & & & \\
Depression + anxiety + & $82.04 \pm 5.36$ & $64.64 \pm 3.43$ & $<0.000$ I \\
high burnout $(n=25)$ & & & \\
Only CHF $(n=20)$ & $83.15 \pm 7.76$ & $65.20 \pm 3.20$ & $<0.000$ I \\
\hline
\end{tabular}

Notes: $* \chi^{2}$ test. Data presented as mean \pm standard deviation.

Abbreviation: $\mathrm{CHF}$, chronic heart failure.

symptoms were significantly worsened in patients with depression and high burnout status at the 1st month follow-up and remained stable throughout the study frame $(9.00 \pm 0.00 \mathrm{vs}$ $12.93 \pm 1.48$, baseline vs 12 th month; $P \leq 0.0001$; Table 3 ).

\section{Anxiolytic effects of metoprolol}

In contrast to the depressive effects, metoprolol exerted positive effects in CHF patients with anxiety. At baseline, all the four groups with anxiety disorder had significantly high HADS scores compared with patients who had normal mental status (only CHF) ( $P \leq 0.0001$ for all four groups). The HADS anxiety score significantly decreased from baseline in the 3rd month, which remained stable through the 6th and 12th months of follow-up ( $P \leq 0.0001$ for all four groups; Table 3).

\section{High burnout status post-metoprolol treatment}

At baseline, patients with high burnout had high CBI average scores compared to patients with normal mental status ( $P \leq 0.0001$ for all four groups). The burnout score increased significantly from baseline post-metoprolol treatment in the 3rd month, which remained stable through 12 months ( $P \leq 0.0001$ for all four groups). However, a significant increase in CBI score was observed even at the 1st month follow-up period in patients with anxiety + high burnout $(66.47 \pm 0.90$ vs $68.05 \pm 3.56 ; P=0.055)$ and depression + high burnout ( $66.67 \pm 0.00$ vs $68.89 \pm 3.81 ; P=0.032)$, indicating worsening of burnout syndrome (Table 3 ).

\section{Correlation of HR reduction with change in mental status}

Regression analysis to study the impact of HR reduction by metoprolol on change in mental status revealed no significant correlation in any of the groups between HR reduction and change in HADS/CBI scores. However, change in the CBI 
Table 3 Change in mental status post-metoprolol treatment

\begin{tabular}{|c|c|c|c|c|c|}
\hline Groups & Baseline & Month I & Month 3 & Month 6 & Month I2 \\
\hline \multicolumn{6}{|l|}{ HADS depression average scores } \\
\hline Depression & $10.00 \pm 0.20$ & $10.76 \pm 1.78 *$ & $10.92 \pm 1.77 *$ & $10.92 \pm 1.77 *$ & $10.88 \pm 1.69 *, \#$ \\
\hline Anxiety & - & - & - & - & - \\
\hline High burnout & - & - & - & - & - \\
\hline Depression + anxiety & $13.64 \pm 2.20$ & $13.82 \pm 1.59$ & $13.88 \pm 1.40$ & $13.76 \pm 1.43$ & $13.70 \pm 1.40^{\#}$ \\
\hline Anxiety + high burnout & - & - & - & - & - \\
\hline Depression + high burnout & $09.00 \pm 0.00$ & $12.00 \pm 2.6 \mid * *$ & $12.53 \pm 2.13^{* *}$ & $12.46 \pm 2.13^{* *}$ & $12.93 \pm 1.48 * *, \#$ \\
\hline Depression + anxiety + high burnout & $11.56 \pm 0.50$ & $11.68 \pm 0.69$ & $11.68 \pm 0.69$ & $11.68 \pm 0.69$ & $11.56 \pm 0.50^{\#}$ \\
\hline Only CHF & $06.05 \pm 0.22$ & $07.25 \pm 1.48$ & $07.25 \pm 1.48$ & $07.45 \pm 1.46$ & $07.75 \pm 0.96$ \\
\hline \multicolumn{6}{|l|}{ HADS anxiety average scores } \\
\hline Depression & - & - & - & - & - \\
\hline Anxiety & $|0.80 \pm 1.5|$ & $10.46 \pm 1.50$ & $08.40 \pm 0.82 * *$ & $08.26 \pm 0.79 * *$ & $07.73 \pm 0.79 * * \#$ \\
\hline High burnout & - & - & - & - & - \\
\hline Depression + anxiety & $10.23 \pm 1.52$ & $10.17 \pm 1.46$ & $08.00 \pm 0.79 * *$ & $07.88 \pm 0.78 * *$ & $07.64 \pm 0.60 * *, \#$ \\
\hline Anxiety + high burnout & $09.76 \pm 0.43$ & $09.7 I \pm 0.46$ & $07.38 \pm 0.58 * *$ & $07.38 \pm 0.58 * *$ & $07.80 \pm 0.8 I^{* *, \#}$ \\
\hline Depression + high burnout & - & - & - & - & - \\
\hline Depression + anxiety + high burnout & $09.56 \pm 0.50$ & $09.48 \pm 0.50$ & $07.68 \pm 0.80 * *$ & $07.52 \pm 0.65 * *$ & $07.80 \pm 0.57 * *, \#$ \\
\hline Only CHF & $06.55 \pm 0.82$ & $06.50 \pm 0.82$ & $06.50 \pm 0.82$ & $06.6 \pm 0.82$ & $06.25 \pm 0.63$ \\
\hline \multicolumn{6}{|l|}{ CBI average scores } \\
\hline Depression & - & - & - & - & - \\
\hline Anxiety & - & - & - & - & - \\
\hline High burnout & $66.67 \pm 0.00$ & $66.67 \pm 0.00$ & $68.75 \pm 3.72 *$ & $68.75 \pm 3.72 *$ & $71.19 \pm 3.23 * *, \#$ \\
\hline Depression + anxiety & - & - & - & - & - \\
\hline Anxiety + high burnout & $66.47 \pm 0.90$ & $68.05 \pm 3.56 *$ & $70.63 \pm 4.26 * *$ & $70.63 \pm 4.26 * *$ & $70.83 \pm 2.94^{* *, \#}$ \\
\hline Depression + high burnout & $66.67 \pm 0.00$ & $68.89 \pm 3.81 *$ & $70.55 \pm 4.30 * * *$ & $7 I .11 \pm 4.30^{* * *}$ & $71.77 \pm 2.81 * *, \#$ \\
\hline Depression + anxiety + high burnout & $64.33 \pm 2.11$ & $65.33 \pm 2.87$ & $70.16 \pm 4.91 * *$ & $70.16 \pm 4.91 * *$ & $68.00 \pm 5.60 * * * *, \#$ \\
\hline Only CHF & $50.4 I \pm I .86$ & $50.4 I \pm 1.86$ & $50.4 I \pm I .86$ & $50.4 I \pm 1.86$ & $52.50 \pm 2.83$ \\
\hline
\end{tabular}

Notes: $* P \leq 0.05, * * P \leq 0.0001, * * * P \leq 0.001$, ****P $\leq 0.01$ : compared to baseline values; ${ }^{*} P \leq 0.000 \mathrm{I}$ : compared to values of only $\mathrm{CHF}$ group.

Abbreviations: HADS, Hospital Anxiety and Depression Scale; CHF, chronic heart failure; CBI, Copenhagen Burnout Inventory.

scores in patients with depression was significantly $(P=0.01)$ associated with reduction in HR (Table 4). The mechanistic study and validation are warranted in future studies.

\section{Discussion}

In the present study, we examined the impact of metoprolol treatment on the mental status of CHF patients. The study findings do not support an association between metoprolol

Table 4 Correlation between HR reduction and change in mental status in 12th month

\begin{tabular}{llll}
\hline Groups & $\begin{array}{l}\text { HADS } \\
\text { depression }^{\mathrm{a}}\end{array}$ & $\begin{array}{l}\text { HADS } \\
\text { anxiety }^{\mathrm{a}}\end{array}$ & CBI $^{\mathrm{a}}$ \\
\hline Depression & 0.32 & 0.07 & 0.01 \\
Anxiety & 0.55 & 0.48 & 0.94 \\
High burnout & 0.82 & 0.06 & 0.78 \\
Depression + anxiety & 0.55 & 0.21 & 0.15 \\
Anxiety + high burnout & 0.62 & 0.61 & 0.67 \\
Depression + high burnout & 0.74 & 0.26 & 0.40 \\
Depression + anxiety + high burnout & 0.90 & 0.92 & 0.52 \\
Only CHF & 0.63 & 0.49 & 0.39 \\
\hline
\end{tabular}

Note: a $P$-values for regression analysis coefficients.

Abbreviations: HR, heart rate; HADS, Hospital Anxiety and Depression Scale; $\mathrm{CBI}$, Copenhagen Burnout Inventory; CHF, chronic heart failure. use and symptoms of anxiety or depression in CHF patients as these aspects have been extensively studied in previous literature. ${ }^{17,19-21}$ However, there is no evidence on the impact of metoprolol treatment on mental status in CHF patients with clinically diagnosed depression or anxiety disorder. In addition, to the best of our knowledge, this study is the first to investigate the impact of metoprolol treatment on burnout status in CHF patients.

Patients with CHF have clinically significant depression and anxiety two- to three fold higher than that of the general population with a prevalence of $30 \%-50 \%,{ }^{27-29}$ and thereby present a potential challenge in successful CHF treatment. Unfortunately, depression and anxiety go unrecognized while diagnosing and prescribing medications to treat $\mathrm{CHF}$ owing to the overlap of CHF symptoms such as fatigue, poor sleep, and weight changes with depressive symptoms such as insomnia and psychomotor retardation. ${ }^{30}$ The treatments intended for CHF may impose side effects on CNS, thereby worsening or improving the mental status. Studies have found that $\beta$ blockers have to be lipophilic and able to cross the blood-brain barrier to exert neuropsychological side effects. ${ }^{31}$ Metoprolol, a moderately lipophilic $\beta$ blocker commonly 
prescribed for CHF, also prevents a part of pressor response to psychological stress. ${ }^{32}$ Studies suggest that depression is associated with a poor prognosis of survival in CHF patients, and antidepressant treatment has shown only modest or no improvements in outcomes. ${ }^{33}$ Furthermore, randomized trials have shown failure of nonpharmacologic strategies in the treatment of depression in CHF patients. ${ }^{34,35}$ Hence, there is paucity of data on safe and efficacious treatment of depression with HF. This study finding further suggests that use of metoprolol in the treatment of CHF rapidly worsens the existing depressive symptoms in CHF patients. However, the mechanism by which metoprolol worsens depression is unclear. We tried to correlate the reduction in HR by metoprolol with the change in mental status and found no correlation between the indices, explaining HR independent effects on CNS. It is just assumable that CHF patients are likely to take other drugs such as antihypertensives or antiarrhythmic drugs, which may explain the side effects of metoprolol as a consequence of pharmacokinetic interactions. ${ }^{36}$ One more hypothesis may be the role of metabolizing enzymes, as studies report high adverse events of metoprolol in patients with low CYP2D6 activity. ${ }^{37}$ Hence, the use of metoprolol in CHF patients with depression must be cautiously chosen, and future studies are warranted to study the effect of combined antidepressant and $\beta$ blocker therapy on outcomes in $\mathrm{CHF}$ patients with depression. This study is confined to elderly CHF patients who often present with comorbid diseases such as depression and anxiety. ${ }^{38}$

Anxiety has been related to the increased incidence of sudden death in patients with $\mathrm{CHF} .{ }^{39}$ Animal studies indicate that $\beta-1$ selective adreno-receptors (b1-AR) in basolateral amygdala mediate anxiety-like behavior and that inhibition of these receptors by b1-AR blockers could produce anxiolytic effects. ${ }^{19}$ Further research on human subjects has proved the anxiolytic effects of a $\beta$ - 1 selective adrenergic blocker, metoprolol. ${ }^{20,21}$ However, whether this benefit is translated in CHF patients with anxiety remains obscure. From our investigation, we report rapid and significant improvement of anxiety disorder, suggesting anxiolytic benefits of metoprolol in CHF patients. Furthermore, emotional stress due to depression or anxiety results in burnout syndrome manifested as fatigue and exhaustion. It is believed that burnout syndrome may be an overlap of depression or anxiety disorders. ${ }^{23}$ For the first time, we attempted to study the impact of metoprolol treatment on burnout status of CHF patients and found that metoprolol significantly worsens the already existing high burnout. Although our study shows small differences in statistical significance, the representativeness of clinical significance is questionable owing to the very small sample sizes of groups, which is majorly due to enrollment at a single-center design where the number of patients with HF who received metoprolol was limited and not all patients agreed to provide informed consent for this study. However, of note, baseline was very balanced among the majority of the patients. Hence, we are confident that there were no baseline differences in HF severity and mental status that would have biased the comparison between the groups. Also, previous studies of Cucchini et al, ${ }^{40}$ Eichhorn et al, ${ }^{41}$ and de Figueiredo Neto et $\mathrm{al}^{42}$ used a population of similar size to elucidate the cardiovascular effects of metoprolol in patients with cardiovascular diseases. These studies indicate that a sample size of 15-20 patients might be sufficient to translate the findings to clinically significant data. However, large-sized studies may be warranted to prove our evidence right.

Overall, we suggest that depression, anxiety, and burnout status must be recognized in CHF patients prior to prescribing metoprolol by improving the sensitivity of mental health screening. However, the findings of this study should be interpreted cautiously as the study is limited by a number of factors. The small sample size may not be adequately powered to conclude the findings, warranting future largesize studies. Furthermore, the role of antidepressants on metoprolol-induced changes in mental status was not studied, which is very important as antidepressant therapies themselves do not benefit cardiac outcomes, and metoprolol effects may vary in their presence. We used a study design that could not assess the cause of the effect, and long-term effects of $\beta$ blockers on mental status remain unclear. Also, the impact of changed mental status on cardiac outcomes is obscure, warranting further investigation. Furthermore, we relied on self-report measures to assess anxiety and depression rather than a clinical diagnostic interview. It is likely that many patients may not have accurately reported their mental status or may have been overlooked by the investigators. However, the HADS was specifically designed to avoid false positives when administered in hospital settings and therefore focuses on psychological and cognitive symptoms rather than somatic symptoms or sleep and appetite disturbance. ${ }^{43}$ Furthermore, the tools have standardized and validated psychometric properties in Chinese patients, ensuring reliable assessment. ${ }^{44,45}$ Finally, we assumed that the metoprolol effects were mediated through the reduction in HR, and hence we studied the correlation between HR reduction and mental status without adjusting for general confounders such as age, gender, CHF severity, and so on. Hence, further studies need to investigate the correlation of 
all the associated factors of metoprolol treatment with the changes in mental status, and this study finding may provide a preliminary report on the possible outcomes.

\section{Conclusion}

Metoprolol treatment significantly worsens the depressive and high burnout symptoms, but affords anxiolytic benefits independent of HR reduction in CHF patients with clinically diagnosed mental disorders. Hence, physicians need to be vigilant with regard to the potential presentation of mental disorders in CHF patients while prescribing metoprolol.

\section{Author contributions}

All authors contributed equally to the study and development of the manuscript. YM and XL conceptualized and designed the study. XL and XC were involved in data collection and analysis. All authors contributed toward data analysis, drafting, and critically revising the paper and agree to be accountable for all aspects of the work.

\section{Disclosure}

The authors report no conflicts of interest in this work.

\section{References}

1. Yohannes AM, Willgoss TG, Baldwin RC, Connolly MJ. Depression and anxiety in chronic heart failure and chronic obstructive pulmonary disease: prevalence, relevance, clinical implications and management principles. Int J Geriatr Psychiatry. 2010;25(12):1209-1221.

2. The Cardiac Insufficiency Bisoprolol Study II (CIBIS-II): a randomised trial. Lancet. 1999;353(9146):9-13.

3. Effect of metoprolol $\mathrm{CR} / \mathrm{XL}$ in chronic heart failure: metoprolol $\mathrm{CR} / \mathrm{XL}$ randomised intervention trial in congestive heart failure (MERIT-HF). Lancet. 1999;353(9169):2001-2007.

4. Hjalmarson A, Goldstein S, Fagerberg B, et al. Effects of controlledrelease metoprolol on total mortality, hospitalizations, and well-being in patients with heart failure: the metoprolol $\mathrm{CR} / \mathrm{XL}$ randomized intervention trial in congestive heart failure (MERIT-HF). MERIT-HF Study Group. JAMA. 2000;283(10):1295-1302.

5. Packer M, Fowler MB, Roecker EB, et al. Carvedilol Prospective Randomized Cumulative Survival (COPERNICUS) Study Group. Effect of carvedilol on the morbidity of patients with severe chronic heart failure: results of the carvedilol prospective randomized cumulative survival (COPERNICUS) study. Circulation. 2002;106(17): 2194-2199.

6. Heidenrich PA, Lee TT, Massie BM. Effect of beta-blockade on mortality in patients with heart failure: a meta-analysis of randomized clinical trials. J Am Coll Cardiol. 1997;30(1):27-34.

7. Australia/New Zealand Heart Failure Research Collaborative Group. Randomized, placebo-controlled trial of carvedilol in patients with congestive heart failure due to ischaemic heart disease. Lancet. 1997; 349 (9049):375-380.

8. Goldstein G, Materson BJ, Cushman WC, et al. Treatment of hypertension in the elderly: II. Cognitive and behavioral function. Results of a Department-of-Veterans-Affairs cooperative study. Hypertension. 1990; 15(4):361-369.

9. Head A, Kendall MJ, Ferner RC. Eagles acute effects of beta blockade and exercise on mood and anxiety. Br J Sports Med. 1996;30(3): $238-242$.
10. Gerstman BB, Jolson HM, Bauer M, Cho P, Livingston JM, Platt R. The incidence of depression in new users of beta-blockers and selected antihypertensives. J Clin Epidemiol. 1996;49(7):809-815.

11. Ko DT, Hebert PR, Coffey CS, Sedrakyan A, Curtis JP, Krumholz HM. Beta-blocker therapy and symptoms of depression, fatigue, and sexual dysfunction. JAMA. 2002;288(3):351-357.

12. Avorn J, Everitt DE, Weiss S. Increased antidepressant use in patients prescribed beta-blockers. JAMA. 1986;255(3):357-360.

13. Ahmed AI, van Mierlo P, Jansen P. Sleep disorders, nightmares, depression and anxiety in an elderly patient treated with low-dose metoprolol. Gen Hosp Psychiatry. 2010;32(6):646.e5-e7.

14. Muzyk AJ, Gagliardi JP. Do beta blockers cause depression? Curr Psychiatry. 2010;9(5):50-55.

15. Burkauskas J, Noreikaite A, Bunevicius A, et al. Beta-1-selective beta-blockers and cognitive functions in patients with coronary artery disease: a cross-sectional study. J Neuropsychiatry Clin Neurosci. 2016; 28(2):143-146.

16. Ranchord AM, Spertus JA, Buchanan DM, Gosch KL, Chan PS. Initiation of $\beta$-blocker therapy and depression after acute myocardial infarction. Am Heart J. 2016;174:37-42.

17. Cove-Smith JR, Kirk CA. CNS-related side-effects with metoprolol and atenolol. Eur J Clin Pharmacol. 1985;28(Suppl):69-72.

18. Luijendijk HJ, van den Berg JF, Hofman A, Tiemeier H, Stricker BH. $\beta$-blockers and the risk of incident depression in the elderly. $J$ Clin Psychopharmacol. 2011;31(1):45-50.

19. Jakobsen CJ, Blom L. Pre-operative assessment of anxiety and measurement of arterial plasma catecholamine concentrations. The effect of oral beta-adrenergic blockade with metoprolol. Anaesthesia. 1989; 44(3):249-252.

20. Jakobsen CJ, Blom L, Brondbjerg M, Lenler-Petersen P. Effect of metoprolol and diazepam on pre-operative anxiety. Anaesthesia. 1990; 45(1):40-43.

21. Fu A, Li X, Zhao B. Role of beta1-adrenoceptor in the basolateral amygdala of rats with anxiety-like behavior. Brain Res. 2008;1211:85-92.

22. Brouwers C, Christensen SB, Damen NL, et al. Antidepressant use and risk for mortality in 121,252 heart failure patients with or without a diagnosis of clinical depression. Int J Cardiol. 2016;203:867-873.

23. PubMed Health. Depression: What is Burnout Syndrome? Informed Health Online [Internet]. Available from: https://www.ncbi.nlm.nih. gov/pubmedhealth/PMH0072470/. Accessed September 30, 2016.

24. Prosdócimo AC, Lucina LB, Marcia O, et al. Prevalence of burnout syndrome in patients admitted with acute coronary syndrome. Arq Bras Cardiol. 2015;104(3):218-225.

25. Zigmond AS, Snaith RP. The hospital anxiety and depression scale. Acta Psychiatr Scand. 1983;67(6):361-370.

26. Ratnakaran B, Prabhakaran A, Karunakaran V. Prevalence of burnout and its correlates among residents in a tertiary medical center in Kerala India: a cross-sectional study. J Postgrad Med. 2016;62(3):157-161.

27. Kunik ME, Roundy K, Veazey C, et al. Surprisingly high prevalence of anxiety and depression in chronic breathing disorders. Chest. 2005; 127(4):1205-1211.

28. MacMahon KM, Lip GY. Psychological factors in heart failure: a review of the literature. Arch Intern Med. 2002;162(5):509-516.

29. Rutledge T, Reis VA, Linke SE, Greenberg BH, Mills PJ. Depression in heart failure: a meta-analytic review of prevalence, intervention effects, and associations with clinical outcomes. J Am Coll Cardiol. 2006;48(8): $1527-1537$.

30. Rustad JK, Stern TA, Hebert KA, Musselman DL. Diagnosis and treatment of depression in patients with congestive heart failure: a review of the literature. Prim Care Companion CNS Disord. 2013;15(4): PCC.13r01511.

31. van Melle JP, Verbeek DE, van den Berg MP, Ormel J, van der Linde MR, de Jonge P. Beta-blockers and depression after myocardial infarction: a multicenter prospective study. $J$ Am Coll Cardiol. 2006;48(11): 2209-2214.

32. Chaturvedi SK. Metoprolol in management of patients with depression and hypertension. Indian J Psychiatry. 1986;28(2):163-164. 
33. Jiang W, Alexander J, Christopher E, et al. Relationship of depression to increased risk of mortality and rehospitalization in patients with congestive heart failure. Arch Intern Indian J Psychiatry Med. 2001;161(15): 1849-1856.

34. Berkman LF, Blumenthal J, Burg M. Effects of treating depression and low perceived social support on clinical events after myocardial infarction. The enhancing recovery in coronary heart disease patients (ENRICHD) randomized trial. JAMA. 2003;289(23):3106-3116.

35. Frasure-smith N, Lesperance F, Prince RH. Randomized trial of home based psychosocial nursing intervention for patients recovering from myocardial infarction. Lancet. 1997;350(9076):473-479.

36. Davies SJC, Jackson PR, Potokar J, Nutt DJ. Treatment of anxiety and depressive disorders in patients with cardiovascular disease. BMJ. 2004;328(7445):939-943.

37. Wuttke H, Rau T, Heide R, et al. Increased frequency of cytochrome P450 2D6 poor metabolizers among patients with metoprolol-associated adverse effects. Clin Pharmacol Ther. 2002;72(4):429-437.

38. Freedland KE, Carney RM. Psychosocial considerations in elderly patients with heart failure. Clin Geriatr Med. 2000;16(3):649-661.

39. Thomas SA, Friedmann E, Wimbush F, Schron E. Psychosocial factors and survival in the cardiac arrythmia suppression trial (CAST): a re-examination. Am J Crit Care. 1997;6(2):116-126.
40. Cucchini F, Compostella L, Papalia D, De Domenico R, Iavernaro A, Zeppelini R. Trattamento cronico della cardiomiopatia dilatativa con betablocanti. G Ital Cardiol. 1988;18:835-842.

41. Eichhorn EJ, Heesch CM, Barnet JH, et al. Effect of metoprolol on myocardial function and energetics in patients with nonischemic dilated cardiomyopathy: a randomized, doublé-blind, placebo-controlled study. J Am Coll Cardiol. 1994;24:1310-1320.

42. de Figueiredo Neto JA, Mady C, Grupi C. Effects of metoprolol tartrate therapy in patients with heart failure. Arq Bras Cardiol. 2006;87(3): 329-335.

43. Watkins LL, Koch GG, Sherwood A, et al. Association of anxiety and depression with all-cause mortality in individuals with coronary heart disease. J Am Heart Assoc. 2013;2:e00068.

44. Kiropoulos LA, Meredith I, Tonkin A, Clarke D, Antonis P, Plunkett J. Psychometric properties of the cardiac depression scale in patients with coronary heart disease. BMC Psychiatry. 2012;12:216.

45. Wan-Yu Y, Cheng Y, Chiou-Jong C, Pei-Yi H, Kristensen TS. Psychometric properties of Chinese version of Copenhagen burnout inventory among employees in two companies in Taiwan. Int J Behav Med. 2007; 14(3):126-133.
Drug Design, Development and Therapy

\section{Publish your work in this journal}

Drug Design, Development and Therapy is an international, peerreviewed open-access journal that spans the spectrum of drug design and development through to clinical applications. Clinical outcomes, patient safety, and programs for the development and effective, safe, and sustained use of medicines are the features of the journal, which

\section{Dovepress}

has also been accepted for indexing on PubMed Central. The manuscript management system is completely online and includes a very quick and fair peer-review system, which is all easy to use. Visit http://www.dovepress.com/testimonials.php to read real quotes from published authors.

Submit your manuscript here: http://www.dovepress.com/drug-design-development-and-therapy-journal 